\title{
ĐÁNH GIÁ KHẢ NĂNG DỬ BÁO THỜI TIẾT CỦA MÔ HİNH WRF (WEATHER, RESEARCH AND FORECASTING) CHO KHU VỰC NAM BỘ
}

\author{
Lê Ánh Ngọc ${ }^{1}$, Nguyễn Văn Tín ${ }^{1}$, Trần Như Phát ${ }^{1}$, Nguyễn Văn Hồng ${ }^{1}$
}

Tóm tắt: Trong nhũng năm gần đây diễn biến thời tiết ngày càng trở nên phưc tạp hon, việc sư dụng công nghệ, cu thể là các mô hình dụ báo để hỗ trợ trong công việc dụ báo thời tiết trở nên cần thiết. Bài báo này đánh giá khả năng sủ dụng mô hình WRF để dụ báo thời tiết điểm (20 trạm) tù tháng 1-9/2019, kết quả đánh giá cho thấy mô hình WRF đã dụ báo khá tốt truờng nhiệt, sai số MAE dụ báo dao động chủ yếu tù $0,8-2,2^{\circ} \mathrm{C}$. WRF cho dư báo thiên cao vói nhiệt độ tối cao tuyệt đối và thiên thấp với nhiệt độ tối thấp tuyệt đối ở hầu hết các trạm.WRF dụ báo luọng mura thiên cao so với lượng mura thực tế đo được (trù̀ trạm Côn Đảo). Chỉ số MAE dao động tù 9-49mm. Sai số bình phương phương quân dao động tù 16-64mm. Chỉ số dư báo sai (FAR) dao động tù 0,16-0,3, điểm số thành công dao động tù̀ 0,5-0,73 và PC tù 0,6-0,76. WRF dụ báo chura tốt trong tháng 7 và dụ báo khá tốt trong tháng 8 và tháng 9.

Từ khóa: WRF, dụ báo, mưa, nhiệt.

Ban Biên tập nhận bài: 25/10/2019 Ngày phản biện xong: 28/11/2019 Ngày đăng bài: 25/12/2019

\section{1. Đặt vấn đề}

Phương pháp dự báo thời tiết bằng mô hình số đã được sử dụng nhiều nước trên thế giới trong nhiều thập kỉ qua. Những thành tựu dự báo số đem lại đã góp phần nâng cao chất lượng dự báo trong vài thập kỉ trở lại đây. Hiện nay trên thế giới có rất nhiều mô hình dự báo số trị toàn cầu được sử dụng và cho kết quả đáng tin cậy như Hệ thống Dự báo Toàn cầu (Global Forecast System - GFS) của Trung tâm Dự báo Môi trường Quốc gia Mỹ (National Centers for Environmental Prediction - NCEP), Mô hình Môi trường Toàn cầu Đa quy mô (Global Environmental Multiscale - GEM) của Trung tâm Khí tượng Canada (Canada Meteorologycal Centre - $C M C$ ). Các mô hình số trị quy mô vừa như WRF, MM5, RAM, HRM... đã được sử dụng trong nghiên cứu và công tác dự báo thời tiết hàng ngày ở hầu hết các nước phát triển trên thế giới, từ những dự báo thời tiết thông thường đến việc giải quyết các dự báo mưa cả về lượng và về pha [4].

Tại Việt Nam, dự báo mô hình số đã và đang trở thành phương pháp dự báo chủ lực trong nghiệp vụ dự báo thời tiết. Các phương pháp dự báo của mô hình mang lại cho thấy sự khác biệt rõ rệt so với các phương pháp truyền thống (phương pháp Synop), chủ yếu dựa trên các kinh nghiệm, phương pháp dân gian mà đưa ra kết quả. Hiện tại, các mô hình khu vực sử dụng tại Việt Nam đều dựa trên phân tích và dự báo từ các mô hình toàn cầu hoặc hệ thống phân tích dự báo khu vực. Mọi mô hình đều chạy với độ phân giải cao hơn so với độ phân giải từ phân tích và dự báo của mô hình toàn cầu. Điều này đồng nghĩa với việc một vùng phổ nằm giữa độ phân giải của mô hình toàn cầu và mô hình khu vực không được biểu diễn trong số liệu ban đầu cũng như số liệu biên. Hệ thống đồng hóa số liệu sẽ cho phép lấp đầy khoảng trống này, tác động tới chất lượng dự báo.

Với sự phát triển xây dựng và ngày càng hoàn thiện các mô hình dự báo số, hệ thống các mô hình cung cấp một nguồn số liệu dư báo qua trọng cùng với đó là số lượng thông tin lớn cần được kiểm định và đánh giá độ chính xác.Sự ra

'Phân viện Khoa học Khí tuợng Thủy văn và Biến đổi khi hậu

Email: leanhngoc.sihymete@gmail.com; tin.sihymete@gmail.com; phatnhutran1712@gmail.com. 
đời và quá trình phát triển của Mô hình Nghiên cứu và Dự báo Thời tiết - Nghiên cứu Nâng cao (Weather Research and Forecast model - Advanced Research $W R F, W R F-A R W$ ) đánh dấu một bước tiến quan trọng trong dự báo thời tiết khu vực, nâng cao tầm hiểu biết và độ chính xác trong việc nghiên cứu và dự báo các quá trình của khí quyển. WRF là kết quả của sự hợp tác phát triển của nhiều trung tâm nghiên cứu và dự báo khí tượng ở Hoa Kỳ như Trung tâm Quốc gia Nghiên cứu Khí quyển Mỹ (National Center for Atmospheric Research - NCAR), NCEP...và đội ngũ đông đảo các nhà khoa học làm việc tại các trường đại học trên thế giới. Bên cạnh mục đích dự báo nghiệp vụ, WRF còn có thể khả năng áp dụng trong nghiên cứu mô phỏng các điều kiện thời tiết thực.

Nằm trong vùng khí hậu nhiệt đới gió mùa, thời tiết hàng năm ở các tỉnh thành Nam Bộ có hai mùa rõ rệt: mùa khô và mùa mưa, gần như trùng khớp với thời kỳ hoạt động của gió mùa đông bắc và gió mùa tây nam. Mùa mưa thường kéo dài từ tháng $\mathrm{V}$ đến tháng XI hàng năm, với tỷ trọng lượng mưa chiếm khoảng từ 90 đến $95 \%$ tổng lượng mưa cả năm. Sự thay đổi hình thế có thể gây ra các thời tiết khác nhau. Do vậy, việc dự báo kịp thời và chính xác thời tiết tương ứng trên địa bàn là một trong những tính cấp thiết đối với sự phát triển kinh tế xã hội.

\section{Phương pháp nghiên cứu và số liệu sử dụng}

\subsection{Giới thiệu về khu vực nghiên cứu}

Nam Bộ thuộc khu vực phía cực nam của Việt Nam, bao gồm 19 tỉnh chia thành 2 khu vực là Đông Nam Bộ và Tây Nam Bộ. Đông Nam Bộ nằm trên vùng bình nguyên và đồng bằng, nơi chuyển tiếp từ cao nguyên Nam Trung Bộ đến đồng bằng sông Cửu Long với độ cao trung bình 20 - 200m. Tây Nam Bộ địa hình tương đôi bằng phẳng với độ cao trung bình so với mực nước biển từ 3-5m [5]. Nam Bộ đặc trưng bởi khí hậu nhiệt đới gió mùa và cận xích đạo, có 2 mùa rõ rệt mùa mưa và mùa khô. Vào mùa đông khu vực Nam Bộ bị chi phôi bởi gió mùa đông bắc, nhiệt độ trung bình trên $25^{\circ} \mathrm{C}$, lượng mưa thấp, chiếm khoảng $5-10 \%$ tổng lượng mưa năm. Mùa hè bị chi phối bởi giò mùa Tây Nam nhiệt độ trung bình tháng từ $27,5-28^{\circ} \mathrm{C}[5]$.

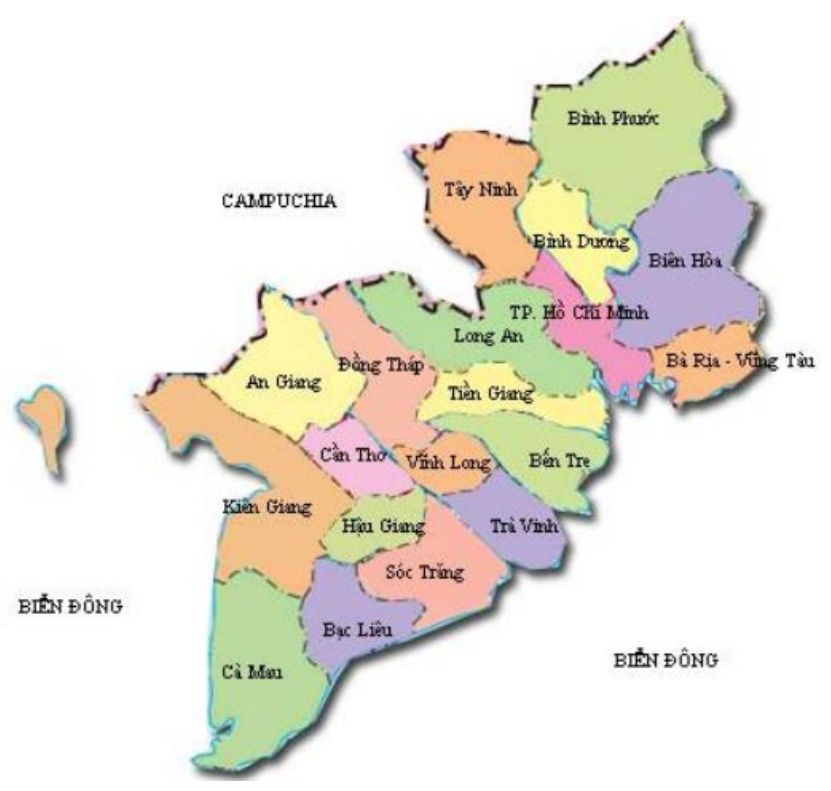

Hình 1. Bản đồ khu vực Nam Bộ

\subsection{Giới thiệu về mô hình WRF}

Mô hình WRF được thiết kế linh động, có độ tùy biến cao và có khả năng vận hành trên những hệ thống máy tính lớn và có thể dễ dàng tùy biến cho cả công việc nghiên cứu và dự báo. WRF có thể mô phỏng khí hậu bằng phương pháp hạ quy mô động lực downscaling (Dynamic downscaling climate simulations), nghiên cứu và đánh giá chất lượng không khí, mô hình kết hợp đại dương - khí quyển và các mô phỏng lý tưởng (như xoáy lớp biên, đối lưu, sóng tà áp,...). Chính vì những ưu điểm như trên, mô hình WRF đang được sử dụng trong nghiên cứu khí quyển và dự báo nghiệp vụ tại Hoa kỳ cũng như nhiều nơi trên thế giới. Bài báo này sử dụng phiên bản mới nhất của WRFV4.0, đây là phiên bản có nhiều cải tiến so với trước: Bao gồm thêm giá trị còn thiếu vào land fields (Nhiệt độ đất, độ ẩm đất,...) [8].

Phương trình chủ đạo của mô hình WRF là hệ phương trình đầy đủ bất thủy tĩnh Euler.Hệ tọa độ theo phương thẳng đứng là hệ tọa độ áp suất. Hệ tọa độ theo phương ngang: lưới xen kẽ Arakawa-C giữa đại lượng có hướng gió $(\mathrm{u}, \mathrm{v})$ và đại lượng vô hướng (nhiệt độ,áp suất).

Các sơ đồ tham số hóa vật lý trong mô hình WRF được chia thành năm loại sau: các quá trình vi vật lý (mô tả các quá trình vật lý hỗn hợp 
pha rắn -lỏng -khí nhằm giải quyết bài toán mây của mô hình), các sơ đồ tham số hóa đối lưu (tham số hóa quá trình đối lưu nông, sâu), các quá trình vậy lý bề mặt (do sự đa dạng của tính chất của lớp phủ bề mặt từ mô hình nhiệt đơn giản cho đến bề mặt có thực vật che phủ hoàn toàn và bề mặt đất trồng ẩm ướt, trong đó bao

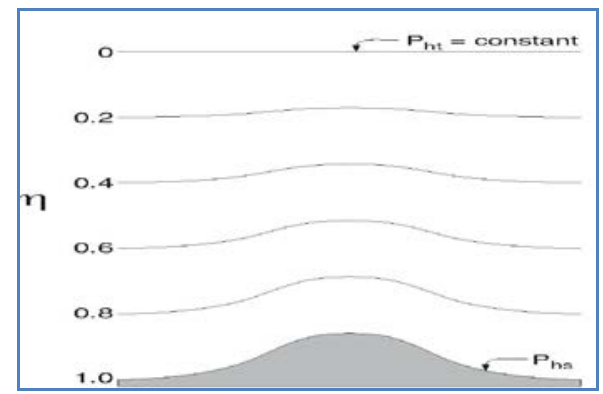

gồm cả bề mặt tuyết phủ và băng biển), các quá trình xảy ra trong lớp biên (để dự báo động năng rối và sơ đồ $\mathrm{K}$ ) và cân bằng bức xạ trong khí quyển (bao gồm hiệu ứng sóng dài và sóng ngắn với dải phổ rộng hoặc chỉ có sóng ngắn, hiệu ứng mây và các thông lượng bề mặt).

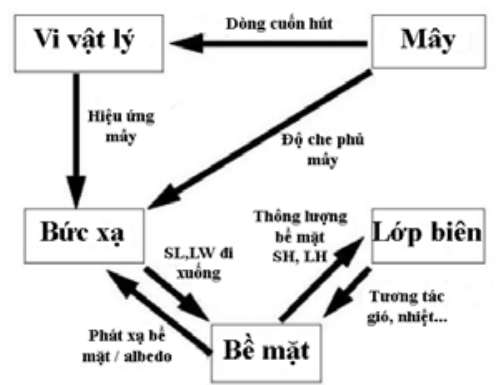

Hình 2. Hệ tọa độ phưong thẳng đứng và tuoong tác vật lý trong WRF

Điều kiện ban đầu của WRF: Mô hình WRFARW có thể chạy đầu vào từ các mô hình toàn cầu như GME (Tổng cục thời tiết, CHLB ĐứcDWD), GFS (Trung tâm dự báo môi trường quốc gia Mỹ-NCEP), GSM (Cơ quan khí tượng Nhật bản-JMA), NOGAPS (Khí tượng Hải quân Mỹ). Trong bài này mô hình được thiết lập bước thời gian $6 \mathrm{~h} / \mathrm{số}$ liệu trong 04 phiên/ngày (00,06,12,18 UTC), độ phân giải gồm $0.18^{\circ} \times 0.18^{\circ}$, số mực áp suất 32 mực, số liệu gồm 21 biến bề mặt (rain, t2m, q2m, um, v10m, cloud, OLR, Tsoil........) và 5 biến trên mực áp suất; Độ cao địa thế $(H)$, gió (U, V), nhiệt độ $(T)$, độ ẩm (Q).

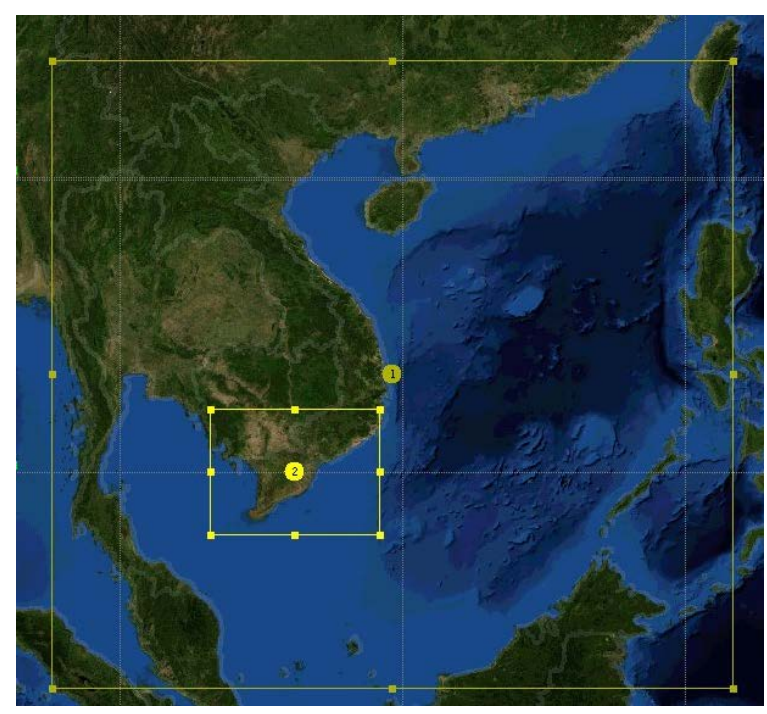

Hình 3. Miền tính của mô hình WRF

\subsection{Thiết lập miền tính và luơơi tính của mô} hình

Miền D01: Bao gồm 130 x 120 điểm lưới, kích thước ô lưới $20 \mathrm{~km}$

Miền D02: Bao gồm 161 x 121 điểm lưới, kích thước ô lưới $4 \mathrm{~km}$

Bảng 1. So đồ tham số hóa vật ký sử dụng trong mô phỏng [1,4]

\begin{tabular}{lc}
\hline Đối lưu & Sơ đồ Kain-Fritsch \\
\hline Bức xạ sóng ngắn & RRTM \\
Bức xạ sóng dăi & Dudhia \\
Lớp biên hành tinh & Mellor-Yamada-Janjic \\
Đất & FAO 8km \\
Bề mặt & Monin-Obukhov \\
Vi vật lý mây & WSM 6-class \\
\hline
\end{tabular}

\subsection{Số liệu sử dụng}

Số liệu đầu vào GFS $0.5^{\circ}$ được lấy từ mô hình toàn cầu tại địa chỉ:

http://para.nomads.ncep.noaa.gov/pub/data/n ccf/com/gfs/para/gfs.yyyymmddhh.

Số liệu nhiệt độ và lượng mưa quan trắc được lấy từ các trạm khí tượng ở Nam Bộ: Tân Sơn Hòa (Tp. Hồ Chí Minh), Bình Dương, Đồng Phú, Tây Ninh, Bà Rịa - Vũng Tàu, Côn Đảo, Mộc Hóa, Mỹ Tho, Ba Tri, Càng Long, Cần Thơ, Sóc Trăng, Rạch Giá, Phú Quốc, Bạc Liêu, Cà Mau.

\subsection{Phưong pháp đánh giá sai số}

Đánh giá theo pha: 


\section{BÀI BÁO KHOA HỌC}

Sai số trung bình (ME): cho biết xu hướng lệch trung bình của giá trị dự báo so với giá trị quan trắc.

$$
\mathrm{ME}=\frac{1}{\mathrm{~N}} \sum_{\mathrm{i}=1}^{\mathrm{N}}\left(\mathrm{F}_{\mathrm{i}}-\mathrm{O}_{\mathrm{i}}\right)
$$

Sai số tuyệt đối trung bình (MAE): biểu thị biên độ trung bìnhcủa sai số mô hình.

$$
\text { MAE }=\frac{1}{N} \sum_{i=1}^{N}\left|F_{i}-O_{i}\right|
$$

Sai số bình phương trung bình quân phương (RMSE): biểu thị độ lớn trung bình của sai số. Nếu RMSE càng gần MAE sai số mô hìnhcàng ổn định và có thể thực hiện việc hiệu chỉnh sản phẩm mô hình.

$$
\text { RMSE }=\sqrt{\frac{1}{N} \sum_{i=1}^{N}\left(F_{i}-O_{i}\right)^{2}}
$$

Trong đó $\mathrm{F}$ là dự báo; $\mathrm{O}$ là quan trắc; $\mathrm{N}$ là tổng số trường hợp.

\section{Đánh giá thống kê theo loại:}

Hits $(\mathrm{H})=$ dự báo có + quan trắc có

False alarms $(\mathrm{F})=$ dự báo có + quan trắc không

Misses $(\mathrm{M})=$ dự báo không + quan trắc có

Correct negatives $(\mathrm{CN})=$ dự báo không + quan trắc không

- Tỷ phần dự báo phát hiện sai (False Alarms Ratio - FAR)

$\mathrm{FAR}=\mathrm{F} /(\mathrm{H}+\mathrm{F})$

Giá trị tối ưu FAR $=0$

- Điểm số thành công (Critical Success Index-CSI hay Threat Score-TS)

$$
\mathrm{CSI}=\mathrm{TS}=\mathrm{H} /(\mathrm{M}+\mathrm{F}+\mathrm{H})
$$

Giá trị tối ưu $\mathrm{TS}=1$

- Độ chính xác (Percentage Correct - PC)

$$
\mathrm{PC}=(\mathrm{H}+\mathrm{CN}) /(\mathrm{M}+\mathrm{F}+\mathrm{H}+\mathrm{CN})
$$

\section{Kết quả và thảo luận}

\subsection{Dư báo thời tiết bằng mô hình số}

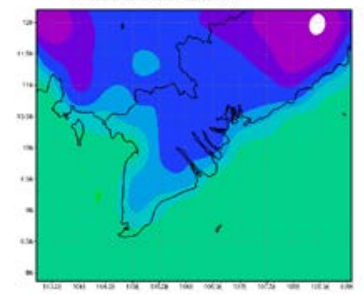

(a)

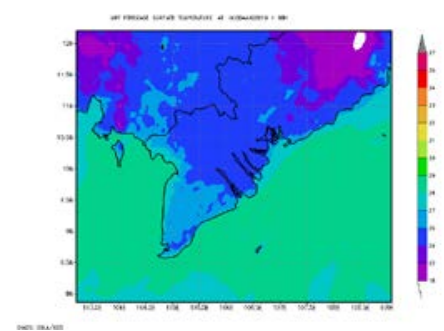

(d)

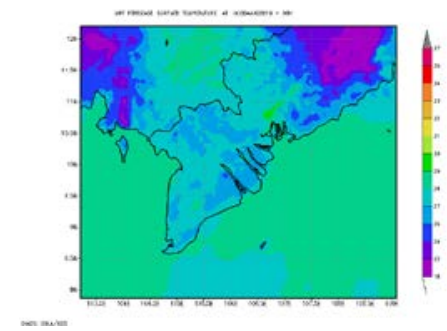

(g)

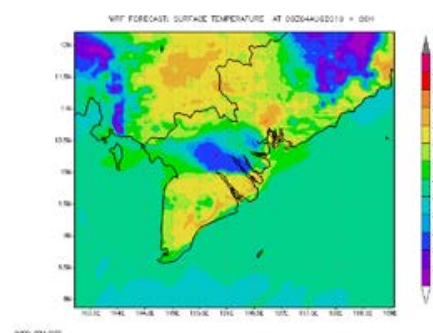

(b)

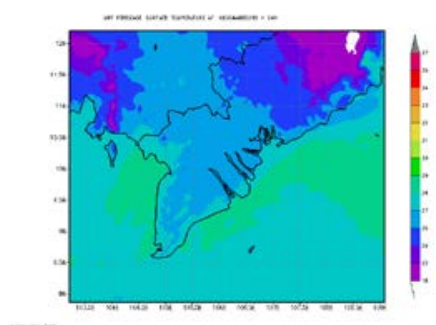

(e)

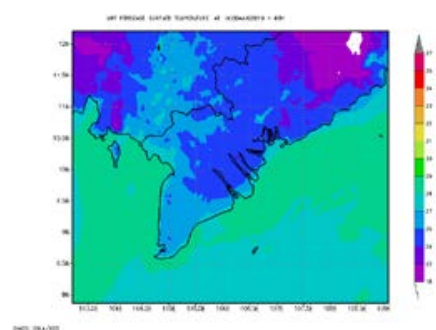

(h)

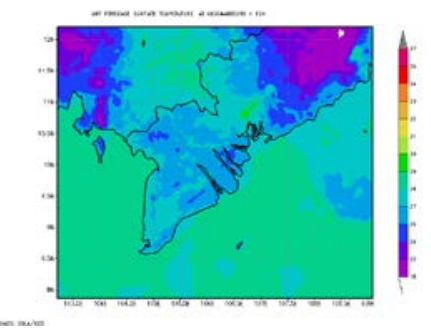

(c)

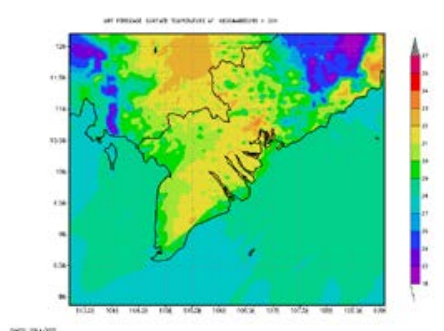

(f)

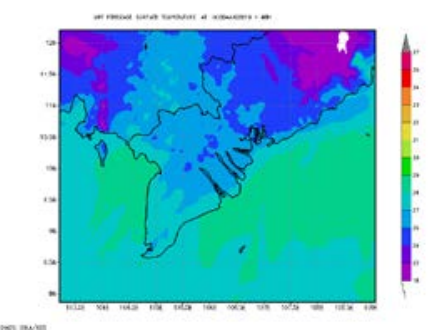

(i)

Hình 4. Nhiệt độ ngày 04/08/2019 lúc 7h dụ báo trong 48 giờ tiếp theo: (a) Nhiệt độ ngày 04/08 tại 00zz; (b) Nhiệt độ ngày 04/08 tại 06z; (c) Nhiệt độ ngày 04/08 tại 12z; (d) Nhiệt độ ngày 04/08 tại 18z; (e) Nhiệt độ ngày 04/08 tại 24z; (f) Nhiệt độ ngày 04/08 tại 30z; (g) Nhiệt độ ngày 04/08 tại 36z; (h) Nhiệt độ ngày 04/08 tại 42z; (i) Nhiệt độ ngày 04/08 tại 48z 
Nhiệt độ ngày 04/08/2019 mô hình dự báo nhiệt độ cao nhất từ $33-34^{\circ} \mathrm{C}$ tập trung ở khu vực TP. Hồ Chí Minh các quận như Quận 1, Quận 9.

Nhiệt độ thấp nhất mô hình dự báo khoảng $23-24^{\circ} \mathrm{C}$ ở các khu vực như Củ Chi (TP. HCM), Mỹ Tho (Bến Tre), Cao Lãnh (Đồng Tháp), Càng Long (Trà Vinh), Mộc Hóa (Long An),
Bình Dương, Biên Hòa, Phước Long.

Dự báo mô hình trong 48 giờ tiếp theo nhiệt độ cao nhất khoảng $33-34^{\circ} \mathrm{C}$ vẫn tập trung ở khu vực TP. Hồ Chí Minh, nhiệt độ thấp nhất từ 22$24^{\circ} \mathrm{C}$ ở các khu vực như Sóc Trăng, Cần Thơ, Càng Long, Ba Tri, Cao Lãnh, Mỹ Tho, Mộc Hóa (Long An), Bình Dương, Tây Ninh.

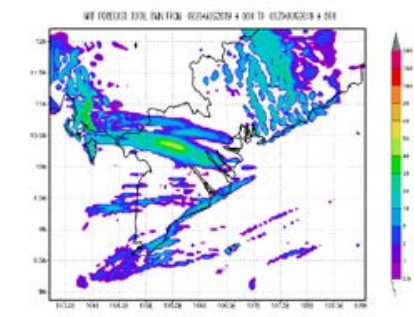

(a)

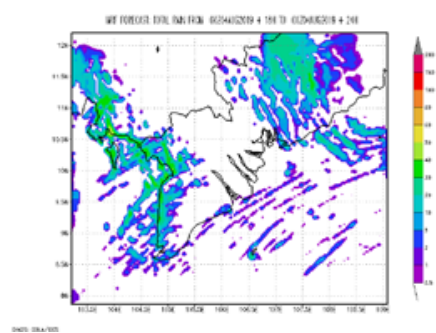

(d)

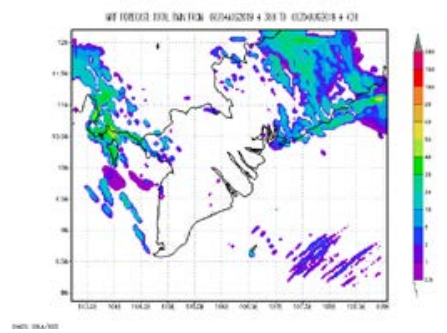

(g)

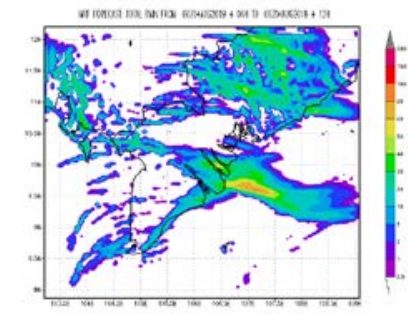

(b)

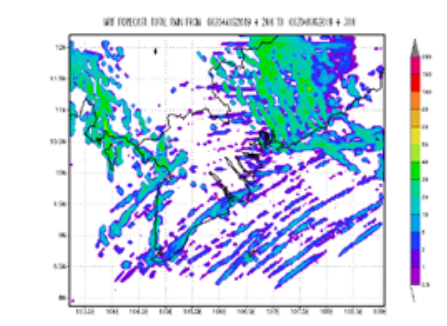

(e)

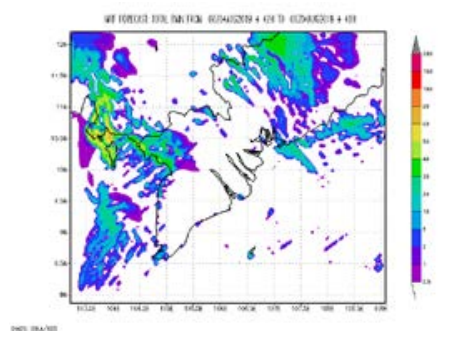

(h)

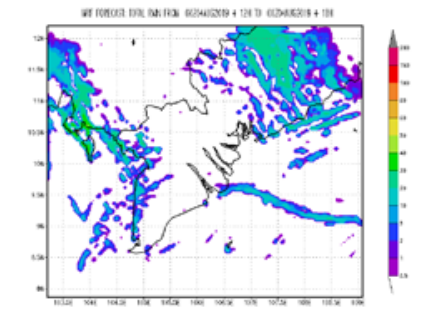

(c)

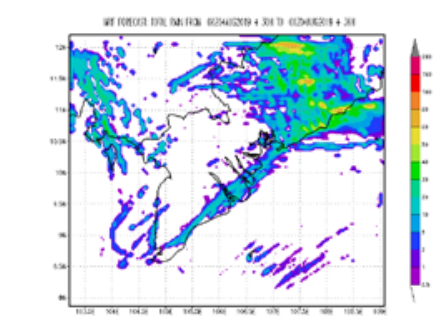

(f)

Hình 5. Lương mưa ngày 04/08/2019 lúc 7 h dụ báo trong 48 giờ tiếp theo: (a) Luợng mưa ngày 04/08 tù 00z - 06z; (b) Lương mưa ngày 04/08 tù 06z - 12z; (c) Lương múa ngày 04/08 tù 12z 18z; (d) Lương mura ngày 04/08 tù 18z - 24z; (e) Lương mura ngày 04/08 tù̀ $24 z$ - 30z; (f) Lương mưa ngày 04/08 tù 30z - 36z; (g) Lượng mưa ngày 04/08 tù 36z - 42z; (h) Lượng mura ngày 04/08 tù $42 z-48 z$

Ngày 04/08/2019 mô hình cho dự báo mưa ở hầu hết các trạm thuộc khu vực Nam Bộ với lượng mua cao nhất ở trạm Phú Quốc với 100,4 mm, trạm Rạch Gía với 59,7mm, trạm Đồng Phú (Bình Phước) với 67,6mm và một số trạm không mưa như Tây Ninh, Cà Mau.
Trong 48 giờ tiếp theo mô hình dự báo cho lượng mưa lớn nhất ở khu vực Phú Quốc (115,1mm), Bà Rịa Vũng Tàu (57,8mm), Đồng Phú (100,1mm), một số trạm dự báo không mưa như Bình Dương, Càng Long (Trà Vinh). 
Bảng 2. Bản tin dụ báo thời tiết điểm ngày 04/08/2019 (00Z)

\begin{tabular}{|c|c|c|c|c|c|c|}
\hline \multirow{2}{*}{$\begin{array}{l}\text { Khu } \\
\text { vực }\end{array}$} & \multirow{2}{*}{ Điểm } & \multirow{2}{*}{ Yếu tố } & \multicolumn{4}{|c|}{ Thời gian dự báo } \\
\hline & & & Ngày04 & Đêm04 & Ngày05 & Đêm05 \\
\hline \multirow{27}{*}{ Đông Nam Bộ } & \multirow{3}{*}{ TP. Hồ Chí Minh } & Nhiệt đô (Đô c) & 33,1 & 25,0 & 33,4 & 24,9 \\
\hline & & Lượng mưa (mm) & 3,0 & 0,0 & 0,4 & 0,0 \\
\hline & & Độ ẩm (\%) & 58,7 & 93,6 & 58,6 & 93,0 \\
\hline & \multirow{4}{*}{ Đồng Phú } & Nhiệt độ (Độ c) & 31,2 & 23,3 & 30,5 & 23,1 \\
\hline & & Lượng mưa (mm) & 30,8 & 36,8 & 70,1 & 30,0 \\
\hline & & Độ ẩm (\%) & 66,8 & 98,3 & 68,5 & 98,4 \\
\hline & & Nhiệt độ (Độ c) & 30,6 & 22,6 & 30,6 & 23,2 \\
\hline & \multirow[t]{3}{*}{ Phước Long } & Lượng mưa (mm) & 0,0 & 8,3 & 3,4 & 2,2 \\
\hline & & Độ ẩm (\%) & 66,5 & 98,9 & 71,7 & 98,9 \\
\hline & & Nhiệt độ (Độ c) & 32,6 & 23,7 & 32,2 & 24,2 \\
\hline & \multirow[t]{3}{*}{ Tây Ninh } & Lượng mưa (mm) & 0,0 & 0,0 & 7,1 & 0,0 \\
\hline & & Độ ẩm (\%) & 61,3 & 98,8 & 63,0 & 98,7 \\
\hline & & Nhiệt độ (Độ c) & 32,2 & 23,9 & 32,3 & 23,6 \\
\hline & \multirow[t]{3}{*}{ Bình Dương } & Lượng mưa (mm) & 3,0 & 0,0 & 0,0 & 0,0 \\
\hline & & Độ ẩm (\%) & 63,7 & 97,3 & 64,0 & 97,5 \\
\hline & & Nhiệt độ (Độ c) & 31,7 & 24,2 & 32,3 & 22,9 \\
\hline & \multirow[t]{3}{*}{ Biên Hòa } & Lượng mưa (mm) & 0,2 & 0,0 & 0,0 & 0,0 \\
\hline & & Độ ẩm (\%) & 65,0 & 95,8 & 60,4 & 97,7 \\
\hline & & Nhiệt độ (Độ c) & 32,5 & 26,3 & 32,1 & 26,3 \\
\hline & \multirow[t]{3}{*}{ BRVT } & Lượng mưa (mm) & 0,2 & 0,3 & 43,2 & 14,6 \\
\hline & & Độ ẩm (\%) & 64,4 & 91,0 & 67,6 & 92,5 \\
\hline & & Nhiệt độ (Độ c) & 29,2 & 26,5 & 28,1 & 26,7 \\
\hline & \multirow[t]{3}{*}{ Côn Đảo } & Lượng mưa (mm) & 0,1 & 0,0 & 1,0 & 0,0 \\
\hline & & Độ ẩm (\%) & 76,4 & 91,4 & 86,1 & 91,1 \\
\hline & & Nhiệt độ (Độ c) & 31,2 & 24,2 & 32,1 & 23,8 \\
\hline & \multirow[t]{3}{*}{ Mộc Hóa } & Lượng mưa (mm) & 0,3 & 0,0 & 0,4 & 0,0 \\
\hline & & Độ ẩm (\%) & 66,9 & 97,4 & 66,2 & 95,9 \\
\hline \multirow{19}{*}{ Tây Nam Bộ } & & Nhiệt độ (Độ c) & 32,2 & 24,4 & 32,7 & 24,3 \\
\hline & \multirow{3}{*}{ Mỹ Tho } & Lượng mưa (mm) & 0,2 & 0,0 & 1,8 & 0,0 \\
\hline & & Độ ẩm (\%) & 62,6 & 95,9 & 60,2 & 97,0 \\
\hline & & Nhiệt độ (Độ c) & 30,7 & 24,2 & 31,0 & 24,2 \\
\hline & \multirow[t]{3}{*}{ Cao lãnh } & Lượng mưa (mm) & 5,8 & 0,0 & 1,9 & 0,1 \\
\hline & & Độ ẩm (\%) & 68,4 & 97,4 & 69,9 & 95,9 \\
\hline & & Nhiệt độ (Độ c) & 32,0 & 23,7 & 32,0 & 23,8 \\
\hline & \multirow[t]{2}{*}{$\mathrm{Ba}$ tri } & Lượng mưa (mm) & 26,1 & 0,0 & 0,1 & 0,0 \\
\hline & & Độ ẩm (\%) & 64,6 & 95,5 & 62,9 & 98,4 \\
\hline & \multirow{2}{*}{ Càng Long } & Nhiệt độ (Độ c) & 31,9 & 23,3 & 31,9 & 24,0 \\
\hline & & Lượng mưa (mm) & 36,0 & 0,0 & 0,0 & 0,0 \\
\hline & \multirow{4}{*}{ Châu Đốc } & Độ âm (\%) & 65,3 & 95,4 & 59,5 & 98,8 \\
\hline & & Nhiệt độ (Độ c) & 32,0 & 24,7 & 31,7 & 25,2 \\
\hline & & Lượng mưa (mm) & 8,6 & 0,0 & 0,1 & 0,0 \\
\hline & & Độ ẩm (\%) & 65,3 & 95,6 & 67,4 & 94,3 \\
\hline & \multirow{4}{*}{ Cần Thơ } & Nhiệt độ (Độ c) & 31,1 & 24,2 & 31,9 & 23,7 \\
\hline & & Lượng mưa (mm) & 2,4 & 0,0 & 0,1 & 0,1 \\
\hline & & Độ ẩm (\%) & 65,6 & 95,7 & 64,8 & 96,4 \\
\hline & & Nhiệt độ (Độ c) & 32,4 & 24,9 & 32,0 & 24,3 \\
\hline
\end{tabular}




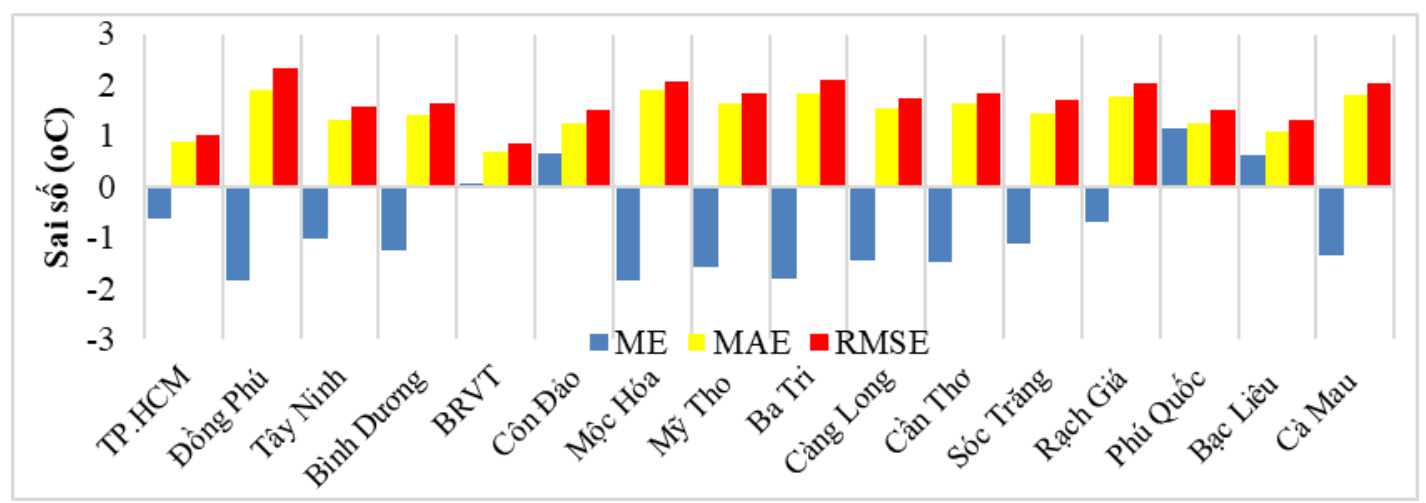

Hình 7. Biểu đồ sai số nhiệt độ tối cao tuyệt đối (Tm)

Hình 6 thể hiện sai số dự báo với Tm, khác với Tx, hầu hết các trạm ở Nam Bộ WRF dự báo Tm thấp hơn so với thực đo (trừ các trạm Côn Đảo, Phú Quốc, Bạc Liêu) cho thấy WRF dự báo Tm thiên thấp so với thực đo. Đối với chỉ số MAE dao động từ $0,85-1,91^{\circ} \mathrm{C}, \mathrm{MAE}$ thấp nhất tại trạm Vũng Tàu, Tân Sơn Hòa và cao nhất tại
Đồng Phú, Mộc Hóa, Ba Tri, Cà Mau

\section{- Đánh giá dự báo lượng mưa:}

Để đánh giá sai số dự báo mưa, bài báo sử dụng các chỉ số đánh giá ME, MAE, RSME, $\mathrm{CSI}, \mathrm{PC}$ và thời gian đánh giá trong các tháng mùa mưa (tháng 7-9/2019).

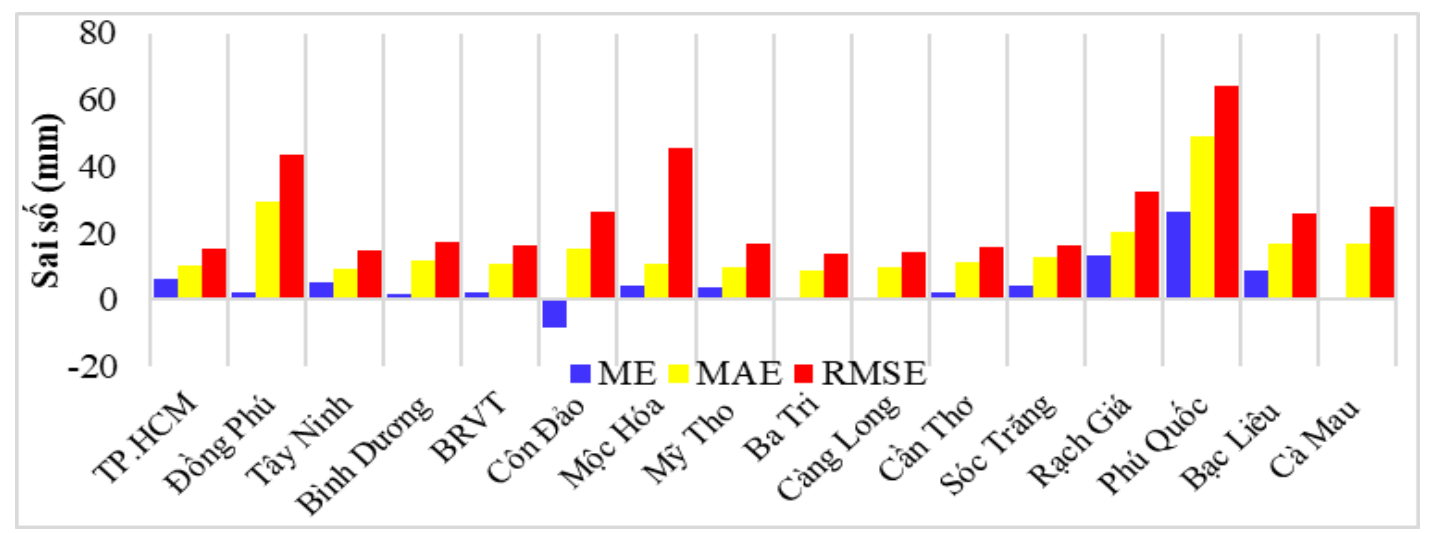

Hình 8. Biểu đồ lượng mura (R)

Từ kết quả đánh giá cho thấy $\mathrm{ME}>0$ ở hầu hết các trạm, như vậy có thể thấy WRF dự báo thiên cao so với lượng mưa thực tế đo được (trừ trạm Côn Đảo). Chỉ số MAE dao động từ 9-49mm, sai số tuyệt đối cao nhất tại trạm Phú Quốc, tiếp đến là Đồng Phú (tỉnh Bình Phước), các trạm còn lại sai số từ $10-20 \mathrm{~mm}$. Sai số bình phương phương quân dao động từ 16-64mm, RMSE cao nhất tại Phú Quốc, tiếp đến là trạm Mộc Hóa và Đồng Phú, các trạm còn lại RMSE dao động từ 15-30mm.

Bảng 3. Điểm số đánh giá mưa trung bình 16 trạm tại Nam Bộ

\begin{tabular}{|c|c|c|c|}
\hline Mô hình Chỉ số & FAR & CSI & PC \\
\hline Tháng $7 / 2019$ & 0,3 & 0,5 & 0,6 \\
\hline Tháng $8 / 2019$ & 0,16 & 0,70 & 0,73 \\
\hline Tháng 9/2019 & 0.18 & 0.73 & 0.76 \\
\hline
\end{tabular}




\begin{tabular}{|c|c|c|c|c|c|c|}
\hline \multirow{16}{*}{$\begin{array}{l}\text { Khu } \\
\text { vực }\end{array}$} & \multirow{2}{*}{ Điểm } & \multirow{2}{*}{ Yếu tố } & \multicolumn{4}{|c|}{ Thời gian dự báo } \\
\hline & & & Ngày04 & Đêm04 & Ngày05 & Đêm05 \\
\hline & \multirow[t]{3}{*}{ Sóc Trăng } & Lượng mưa (mm) & 0,9 & 0,0 & 3,1 & 0,0 \\
\hline & & Độ ẩm $(\%)$ & 62,0 & 92,8 & 59,2 & 97,2 \\
\hline & & Nhiệt độ (Độ c) & 30,6 & 26,5 & 29,6 & 25,9 \\
\hline & \multirow[t]{3}{*}{ Rạch Giá } & Lượng mưa (mm) & 0,0 & 59,7 & 15,2 & 29,4 \\
\hline & & Độ ẩm (\%) & 73,1 & 89,2 & 80,0 & 93,0 \\
\hline & & Nhiệt độ (Độ c) & 29,5 & 27,4 & 29,2 & 27,4 \\
\hline & \multirow[t]{3}{*}{ Phú Quốc } & Lượng mưa (mm) & 36,9 & 63,5 & 36,6 & 78,6 \\
\hline & & Độ ẩm (\%) & 72,1 & 85,2 & 30,5 & 89,3 \\
\hline & & Nhiệt độ (Độ c) & 33,3 & 26,5 & 31,1 & 26,8 \\
\hline & \multirow{3}{*}{ Bạc Liêu } & Lương mưa (mm) & 15,4 & 0,0 & 10,1 & 0,1 \\
\hline & & Độ ẩm (\%) & 56,9 & 89,5 & 71,8 & 88,9 \\
\hline & & Nhiệt độ (Độ c) & 32,6 & 25,5 & 32,1 & 25,7 \\
\hline & \multirow[t]{2}{*}{ Cà Mau } & Lượng mưa (mm) & 0,0 & 0,0 & 0,0 & 0,1 \\
\hline & & Độ ẩm (\%) & 59,2 & 91,9 & 60,7 & 92,2 \\
\hline
\end{tabular}

3.2. Đánh giá khả năng ứng dụng mô hình quả dự báo được so sánh với số liệu quan trắc tại số trị trong dụ báo thời tiết khu vục Nam Bộ 16 trạm và thông qua các chỉ số thống kê để đánh

Tiến hành ứng dụng mô hình số trị để dự báo giá khả năng độ đáng tin cậy của mô hình. thời tiết khu vực Nam Bộ trong năm 2019. Kết • Đánh giá dụ̣ báo nhiệt độ

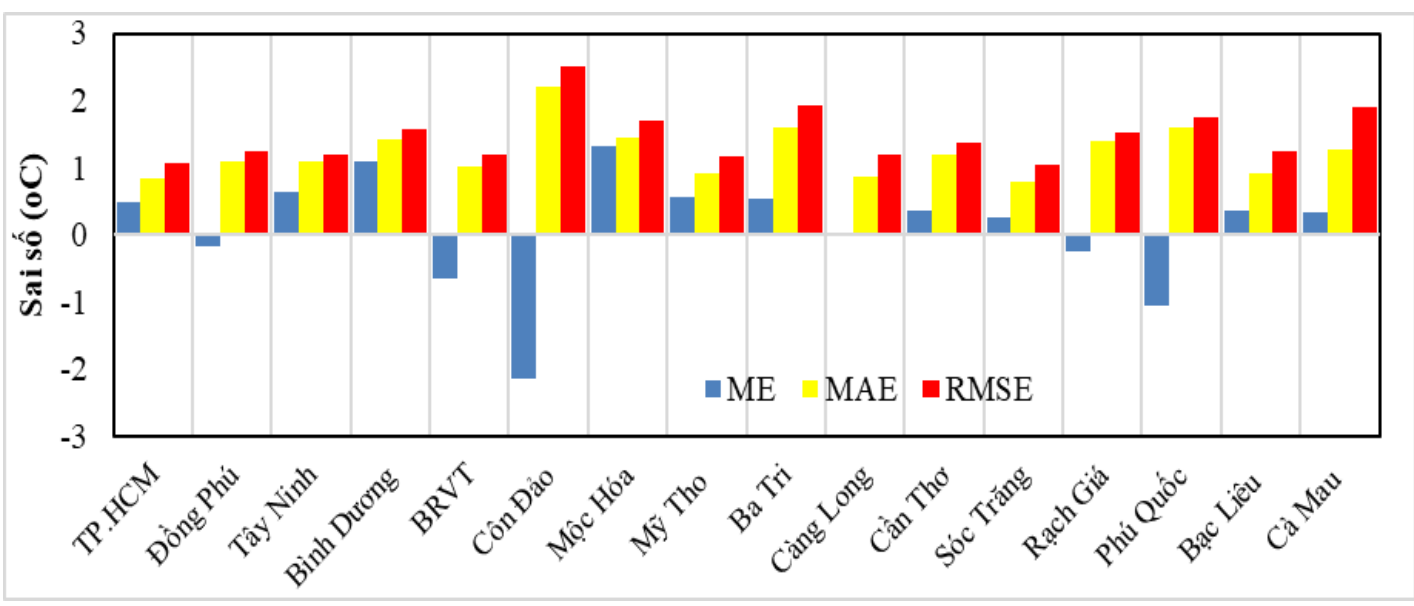

Hình 6. Biểu đồ sai số nhiệt độ tối cao tuyệt đối (Tx)

Sai số dự báo Tx từ tháng 1-9/2019 thể hiện trên Hình 5 cho thấy sai $\mathrm{ME}>0$ ở hầu hết các trạm (trừ Côn Đảo, Vũng Tàu, Rạch Giá, Phú Quốc) cho thấy WRF dự báo thiên cao so với thực đo. MAE dao động từ $0,85-2,2^{\circ} \mathrm{C}$, sai số MAE cao nhất tại trạm Côn Đảo $\left(2,2^{\circ} \mathrm{C}\right)$, tiếp đến là Phú Quốc $\left(1,7^{\circ} \mathrm{C}\right)$, các trạm còn lại dao động từ $0,8-1,5^{\circ} \mathrm{C}$. Như vậy có thể thấy WRF dự báo khá tốt Tx ở Nam Bộ, trừ các trạm ngoài đảo. Về sai số bình phương phương quan (RMSE), cao nhất tại trạm Côn Đảo $\left(2,51^{\circ} \mathrm{C}\right)$ các trạm còn lại dao động từ $1,08-1,7^{\circ} \mathrm{C}$. 


\title{
Tài liệu tham khảo
}

1. Bảo Thạnh và ccs (2014), Nghiên cưu tích hợp các mô hình khí tượng, thủy văn, hải văn nhằm nâng cao chất lượng dụ báo mưc nước trên hệ thống sông Đồng Nai, Đề tài cấp Bộ.

2. Bùi Minh Tăng (2014), Nghiên cứu xây dụng công nghệ dụ báo muxa lớn thời hạn 2-3 ngày phục vu công tác cảnh báo sớm lũ lụt khu vực Trung Bộ Việt Nam. Đề tài cấp nhà nước

3. Phân viện Khoa học Khí tượng Thủy văn và Biến đổi khí hậu (2019), Đánh giá đặc điểm, diễn biến các yếu tố khi tương, thủy văn tại khu vục Nam Bộ trong năm 2019 và khả năng ứng dụng phuoong pháp số trị trong dụ báo khí tuợng, thủy văn.

4. Trương Hoài Thanh, Nguyễn Văn Tín (2011), Khảo sát độ nhạy của các sơ đồ tham số hoá đối lưu trong WRF trong dư báo mura lưu vực sông Sài Gòn - Đồng Nai, Tạp chí KTTV 6/2011.

5. Lê Thông (Cb) (2004), Lê Thông (cb), Nguyễn Văn Phú, Nguyễn Minh Tuệ. Địa lý kinh tế xã hội Việt Nam. - H.: NXB Đại học Sư phạm, 592 tr

6. Lê Văn Thiện, Nguyễn Văn Thắng (2004), Dư báo mua cưc lớn trên khu vưc Việt Nam bằng mô hình WRF. Tuyển tập báo cáo Hội thảo khoa học lần thứ 8 , Viện Khoa học Khí tượng thủy văn và Môi trường.

7. Nguyễn Văn Thắng và cộng sự (2011), Thư nghiệm dụ báo muxa lớn bằng mô hình WRF cho khu vục Bắc Bộ Việt Nam, Hội thảo Quốc tế Gió mùa châu Á tại Đà Nẵng.

8. Wee, T.K., Kuo, Y.H., Lee, D.K., Liu, Z., Wang, W., Chen, S.Y., (2012), Two overlooked biases of the Advanced Research WRF (ARW) Model in geopotential height and temperature. Monthly Weather Review, 140, 3907-3918.

\section{THE ASSESSMENT OF THE WEATHER PREDICTABILITY OF WRF MODEL FOR SOUTHERN REGION \\ Le Anh Ngoc ${ }^{1}$, Nguyen Van Tin ${ }^{1}$, Tran Nhu Phat ${ }^{1}$, Nguyen Van Hong ${ }^{1}$ \\ ${ }^{1}$ Sub-Institute of Hydrometeorology and Climate Change}

\begin{abstract}
In recent years, as the weather has become more and more complex, application of forecasting models plays an important role in weather forecasting. This paper assesses the ability of the WRF model for weather forecasting at 20 stations in the southern region from January 1 to 2019. The results indicates that the WRF model has a good temperature prediction, for instance, $M A E$ ranges mainly from $0.8-2.2^{\circ} \mathrm{C}$. The WRF tends to provides higher predictions for the Absolute High Temperatures while lower number for the Absolute Minimum Temperatures in most stations. The WRFrainfall forecasting product is likely to present higher prediction results compared to the observed data (except Con Dao Station). MAE index ranges from 9-49mm and RMSE varies from 16-64mm. FAR is from 0.16 to 0.3, CSI ranges from 0.5 to 0.73 and PC varies from 0.6 to 0.76 .
\end{abstract}

Keywords: WRF, temperature, rainfall. 